\title{
Impact of E-Learning Strategy on Students' Academic Performance at Strathmore University, Kenya
}

\author{
P. Neema-Abooki ${ }^{1}$, Alfred Kirigha Kitawi \\ ${ }^{1}$ Makerere University [Corresponding author: pnabooki@yahoo.co.uk], ${ }^{2}$ Strathmore \\ University
}

\begin{abstract}
This study examined the impact of e-learning strategies on students' academic performance at Strathmore University. The purpose of the study was to investigate the methodology, ideologies, output and ecology of ICT strategies and their impact on students' performance. This was done through comparing students' mean scores on courses deploying ICT in their delivery with those that do not. The findings were that the e-learning strategies adopted at the University positively impacted on students' academic performance. However, a digital divide in disfavour of poor students is cutting back on the effectiveness of elearning at the University. The paper discusses recommendations towards improvements in deployment of e-learning.
\end{abstract}

Keywords: Teaching and Learning; E-learning; ICT.

\section{$1 \quad$ Introduction}

E-learning is refers to the use of new technologies in the service of learning and/ or learner support (Laurillard, 2006). It includes the delivery of content via the Internet, intranet, audio- and videotape, satellite broadcast, interactive TV and CD-ROM (Boon et al, 2005). E-learning technologies can be used in three main ways in universities and colleges: technology enhanced classroom teaching; distance education (in a bid to reach more students who cannot gain access to conventional universities); and distributed learning (a mix of deliberately reduced face to face teaching and online learning also called 'the mixed mode' or 'flexible learning'). E-learning can help to encourage learner centeredness. Web et al (2004) cite Kolb's model which involved an approach similar to action research. The approach is geared towards four elements: active 
experimentation, concrete experience, reflective observation and abstract conceptualization.

E-learning strategies require a realization of the changes in both the demand for and supply of e-resources. Developing an e-learning strategy is essential in setting a course that will enable a university, faculty or department to achieve predetermined goals (Engelbrecht, 2003). It should be about providing a solution; a return on expectation; enabling learning and driving performance; motivating learners and encouraging organisations; and ensuring that it becomes interwoven into the fabric of the entire institution (Dublin, 2004). The models developed for these strategies undergo a five phase process: initial stage, planned stage, defined stage, managed stage and optimising stage (Marshall, 2004).

Strathmore University integrated ICT's into its operations. It has a distance learning centre that relies on ICT to deploy its course materials. It also employs a mixed method of course delivery that blends online and face-to-face modes. The implementation, management and improvement of e-learning are presumed to have (positive) effects on student performance. In spite of ICT being integrated within the functions of Strathmore University, a study to investigate its impact on students' performance had not been carried out. There had been increased emphasis on keeping abreast with the latest advances in technology. However, it was only taken for granted that it had a positive impact on teaching and learning. Therefore, this study was conducted to investigate: the methodology; ideologies; output; and ecology of the University's ICT strategy and their impact on students' performance.

\section{$2 \quad$ Related Literature}

The area of e-learning is influenced by the ontological perceptions of the individual. The ontological perception of the individual will influence the principles, epistemology, methodology and the way e-learning is implemented to produce results. A positivistic approach which views reality in quantifiable terms, will affect the formulation and implementation of an e-learning strategy. The adoption of the constructivist/interpretive approach will also have its own approach. This was highlighted by Jefferies, Carstern-Stahl \& McRobb (2007) who affirmed that the use of virtual learning tools (emails, tutorials, quizzes, web pages and PowerPoint) can all be related to a positivistic pedagogy, while the use of discussion boards foster social constructivist pedagogy. Successful e-learning implementation depends on building a strategy that meets the needs of the learners and the business goals of the institution (Engelbrecht, 2003). 


\subsection{Theoretical Framework}

E-learning is an off-shoot of information technology 'cyperbole'. Interest in elearning has been facilitated with the rapidly developing technologies. These technologies have experienced ideological 'followers' and 'foes'. The 'devotees' of ICT and e-learning tend to over-emphasize the impact of these technologies, while on the other side, 'adversaries' of ICT are sceptical about the impact of such technologies. The 'techies' insist that ICT's lead to globalisation and the knowledge economy, while the critical theorists insist that although ICT's have an impact, the human-social element should drive the implementation of these technologies.

ICTs are presented as co-terminus with the mechanisms of globalisation, and with this, comes the need for new forms of labour power. ICT's are both presented as cause and a consequent driver for change within Higher Education (Cleg, Hudson \& Steel, 2003). E-learning has been deemed as a 'saviour' in the current 'hype' of massification of higher education.

Sharpe, Benfield and Francis (2006) gives an e-learning strategy that incorporates three modes: Mode 1 was the baseline course administration and learner support; Mode 2 blended learning leading to significant enhancements to learning and teaching process; and Mode 3 which was an online course module. The result was some success due to elements of effective interventions like contextualisation, community and teacher beliefs. Strategies of implementing e-learning can vary significantly. They can be reactive or proactive; moderate or radical (Salmon 2005); incremental or transformative; topdown or bottom up and in some instances mixed. The choices of strategies are influenced by intra and inter organisational factors. In the case where the university is technology intensive, it might wish to distinguish between 'the core' and 'the periphery' in the choice and implementation of its strategies.

Pope (2002) conceptualized e-learning strategies according to Michael Porter's five market forces. The questions crucial in formulating strategies included: What is the bargaining power of suppliers? What is the bargaining power of buyers? What are the possible threats from new entrants? What are the threats from substitute products? What is the rivalry from existing firms? This framework applies mostly in universities which adopt an entrepreneurial model or an adaptive-reactive model. It will be less applicable to the traditional oncampus university.

The aim of the e-learning strategy is to encourage learning. The researchers conceive learning as the process of forming the speculative and practical intellect with all the human appetites that are provided in the classical anthropological view of man. This is done after producing a synthesis of a number of learning approaches: Dewey's pragmatic learning approach, Piaget's constructivism, Vygotsky's social constructive theory, Bruner's discovery 
learning, Marton's deep learning, Bloom's taxonomy and Schank's problem based learning. Weitl et al (2002) concur that for e-learning projects to be successful, e-learning needs to take different learning styles into account. Their conceptualisation of a learning unit consists of the didactical metadata and didactical units. Didactical metadata contains helpful information about a learning unit to support the learner in finding the appropriate unit (getting started) (i.e. pre-requisites, objectives and related material). It also contains a specification of objectives and relationships to other learning materials plus the external learning environment. Didactical units represent the instructional content to be worked through by the learner presented in a sequential order (i.e. overview information, detailed information, exercises and tests).

\subsection{Conceptual Framework}

The model of the conceptual framework adopted for the study is delineated in Figure 1.

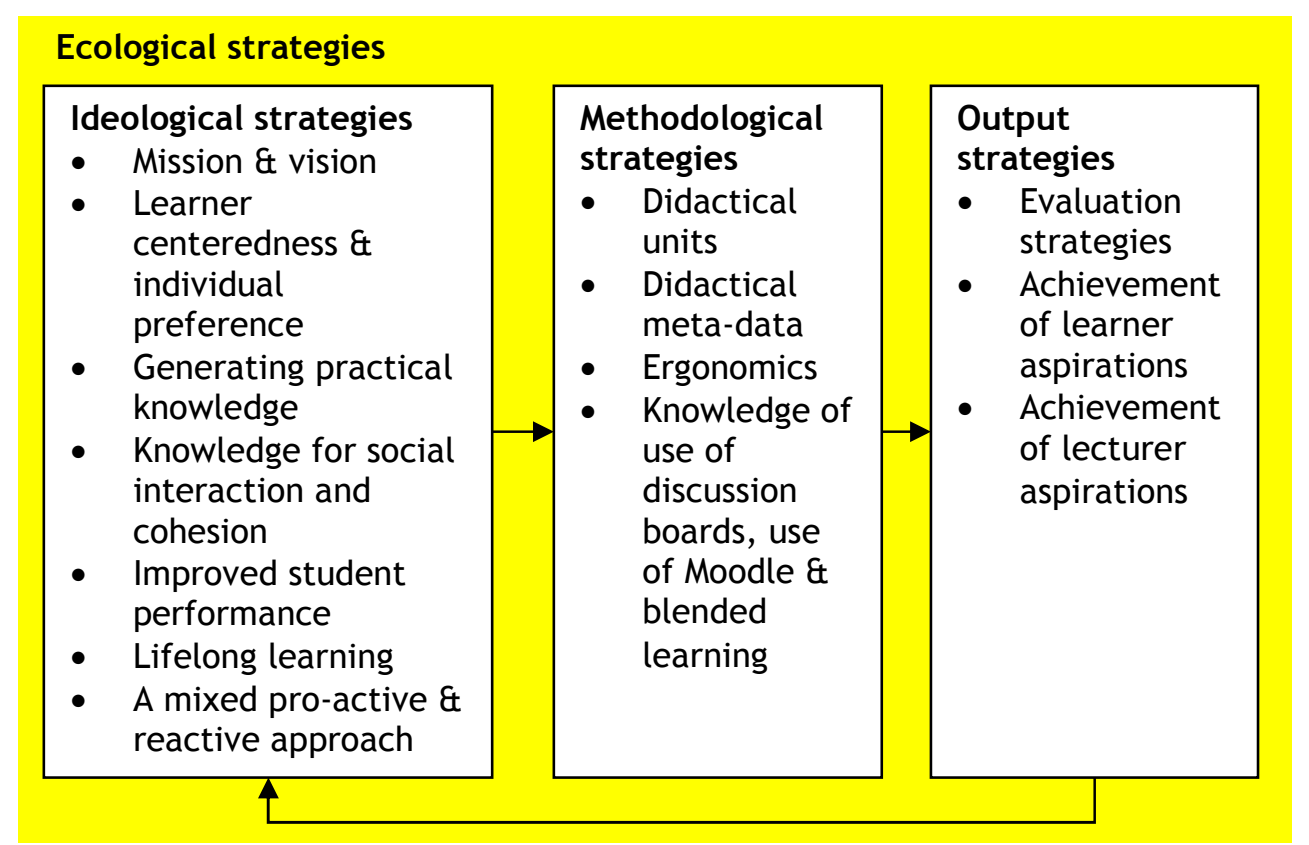

Figure 1: Conceptual model for the study of the Impact of E-learning Strategy on Students' Performance

Source: Adapted from Neema-Abooki and Kitawi (2011)

Ideological strategies deal with the actual conceptualisation of e-learning in line with the university mission and vision. It deals with the formulation and 
formalisation of knowledge principles. If a university conceptualizes itself as an entrepreneurial university, its principles will be different from one which conceives itself as a traditional brick and mortar university or adaptive-reactive university. In turn, its conceptualisation has an influence on which intellectual habits to emphasize on.

Regarding methodological strategies, the relationship between knowledge and knower, will influence the methodological/pedagogical strategies. Some of these strategies are focussed on didactical meta-data, didactical units, ergonomics and knowledge on the use of different technologies.

Output strategies focus on the object of the e-learning process. Materially, this can be the achievement of positive results from summative and formative evaluations. Formally, it can be the actual change that occurs in the learner. It is the knowledge differential before the ideological and methodological strategies have been effected, in comparison to after a student has undergone an e-learning process. It also includes the achievement of learner and lecturer aspirations.

Ecological Strategies deal with the e-learning setting. They take the elearning techniques employed by other universities, the appropriateness of the e-learning technology, competitive and strategic positioning, add-on value to university operations, increased reputation (intangible) and reduction of teaching and learning costs into consideration. The ecological strategies, like an umbrella, have an impact on the ideological, methodological and output strategies.

\section{$3 \quad$ Methodology}

The researchers employed longitudinal surveys to examine statistics on elearning. Questionnaires were also administered. The research was informed by online statistics, student performance for semester one of 2008 and questionnaires answered by students who used some form of e-learning. The researchers opted to compare the results of units which emphasise e-learning with the results from units that had not adopted e-learning for the same students. A sample of 50 students responded to the questionnaire. The questionnaires had four sections. The first section was querying background information and possible extraneous variables. The other four sections sought the influence of the independent variable on the dependent. The researchers were able to get online statistics for the first semester of the 2008/2009 academic year (previous four months). The statistics were deemed crucial because they gave information about the sites visited, the number of visits, the number of hits registered and the users accessing the information. The 
researchers used Ms-Access to sort and manipulate the large amount of data which was initially stored in My-sql. The examination results for the same semester were used as an indication of academic performance. A total of 18 course unit averages were obtained.

\section{$4 \quad$ Findings, Discussion and Conclusions}

\subsection{Online Statistics on Usage of E-Learning}

The average number of hits in the month of August according to web statistics was 134,610. Fifty (50) percent were individuals who were accessing courses to view the contents. This was a fair indicator that most users were actually using the e-learning site. The number of internet users who had accessed the strathmore.edu web-link had increased by 46,443 (53\%) in the last three months. In addition, there had been a small change in the three month average $(78,921)$.

The site report obtained from alexa.com indicated the site is mostly accessed by users within Kenya (89\%). Other frequent users are from India (4\%) and Iran (2\%). The highest ranked sub-domain under the main domain, Strathmore.edu, was elearning.strathmore.edu (43\%). This meant that it was mostly used for learning purposes, compared to others like e-mail access (4\%).

More BBIT (Bachelor of Business Information Technology) students accessed the e-learning $(66,985$ hits, 39,004 course view) site than BCOM (27,233 hits, 11,143 course view), Diploma in Business Information Technology (DBIT) (66,985 hits, 26,292 course view) and IHEDS, Institute for Humanities Education and Development Studies (57,822 hits, 23,337 course view) students. SUES (Strathmore University e-learning System-those engaged in distance learning only) visits showed that many other users, not necessarily registered users, including distance learning students, actually accessed online material $(108,065)$. It was noteworthy to point out the ratio of BCOM to BBIT students was 2:1. The higher student access rate within the BBIT degree might have been due to the nature of course units offered, which were more inclined towards information and web technologies.

The research compared averages for the same population of students. Overall, it appeared that there was a significant difference in class performance when e-learning was used compared to when e-learning was not used. Therefore, it was deduced that was derived from the above data was that elearning contributes to the evening of student performance.

The most noteworthy positive responses were that lecturers informed about the possibility of e-learning (90\%), many students (61\%) concurred with it 
encouraging teaching and learning, the web site was easy to use (53\%) and elearning tools were up-to-date $(65 \%)$. Median responses were recorded for elearning encourages the synthesis and analysis of information (49\%); the materials uploaded and provided were fair and of good quality $(55 \% ; 51 \%)$ and some lecturers gave tests $(47 \%)$ though these tests were not regular $(39 \%)$.

Some students $(49 \%)$ stated that materials related to e-learning were not available; e-learning was not making knowledge practical (23\%); e-learning did not foster interaction and dialogue $(43 \% ; 71 \%)$ and knowledge provided through e-learning was mainly theoretical (76\%). Another response was that $57 \%$ thought e-learning did not reduce expenditure on the part of students. In addition, seventeen (17) students agreed that e-learning does assist in filling of informational gaps through the provision of additional study materials. Two (2) students agreed that e-learning acts as a reference source. Other students (8) explained that e-learning encouraged many students to miss classes, and some form of 'laziness' on the part of the lecturers and students. Some felt that it provided an opportunity for lecturers not to go into detail. The other issue brought out was the 'irrelevant' nature of some materials posted onto the elearning platform.

Some suggestions which were presented to improve and sustain e-learning were: five (5) students indicated the need to provide a clear and consistent information structure; in order to encourage pragmatism, some (5 students) thought that case studies were essential to attain this; Ten (10) students indicated that the hardware resources available in the university were few; twenty-five (25) students indicated that the high expenditures on the part of the students were due to extra printing, surfing and photocopying costs; Some suggested that lecturers provide at least a hard copy which the students can photocopy rather than print; Five (5) students suggested that enrolment keys into e-learning courses should be eliminated.

The students noted that units which tried to incorporate e-learning were mainly Information Technology units like Information System Analysis and Design (ISAD), Programming and Computer Graphics. Within the Institute of Humanities, the units which recorded similar responses were Social and Political Philosophy and Introduction to Ethics.

\subsection{ICT Ideological Strategies impacting on Student Performance}

Majority (61\%) of the students "agreed" that e-learning encouraged teaching and learning; 31 (63\%) students concurred that e-learning helped to achieve course objectives, 26 (53\%) "Disagreed" that e-learning made knowledge more practical, with a further $21(42 \%)$ disputing that e-learning fostered interaction. This meant that the material being provided through e-learning was mainly theoretical. This might have been due to the fact that virtual learning 
environments have not been fully implemented within the e-learning framework. There was need to incorporate tools which facilitated and maintained interaction between the learner-content-lecturer. Indeed, one could have argued that the University had adopted an idealistic approach other than a pragmatic and rationalist view. This was further backed by the finding that 35 (71\%) students thought that e-learning did not encourage dialogue, yet on the other hand, they did agree on the possibility of it fostering teaching and learning. A solid framework suggested by Blass and Davis (2003) needed to be incorporated if e-learning was to achieve the intended benefits. Laurillard (2006) echoed the same when he stated that e-learning has cultural, social, intellectual and practical impacts on learning. Therefore, the University needed to adopt an interactionist strategy when developing and deploying its e-learning tool.

\subsection{ICT Methodological Strategies and Student Performance}

These strategies dealt with the 'how' of e-learning tools. It included ergonomics, course pre-requisites and other related material. The responses to methodological strategies were addressed by eight (8) research questions. Twenty-three (23) (representing 47\%) students stated that the course objectives when integrated with e-learning were unclear. Up to $47 \%$ explained that the course materials were systematically deployed. The quality of e-learning material also required an improvement, since a majority $(51 \%)$ graded the quality of the material as fair. Despite the fact that lecturers try to give many reference sources, 24 (49\%) explained that materials related to e-learning content were unavailable. Engelbrecht (2003) points to the fact that e-learning materials should meet the needs of the learners and business goals. This meant that the lecturers ought to be trained on which methodological strategies to be adopted with the changing circumstances. Web et al (2004) cited the same concern. As regards ergonomics, 26(53\%) agreed that the e-leaning site was easy to use and 19 (39\%) stating that it was appealing to the eye. Despite this, some students expressed the opinion that enrolment keys should be eliminated. This agreed with observations made by Blass and Davis (2003) on the need to incorporate cognitive ergonomics in the design phase. Some students explicated that e-learning material were unsatisfactory $(32.7 \%)$. This meant that there was need to bring together the e-learning course designers with lecturers who used these tools.

\subsection{ICT Ecological Strategies and Student Performance}

The effect of ecological strategies was addressed by four research questions. 20 (41\%) agreed that some form of e-learning was adopted by other universities, 
both public and private. Majority (65\%) concurred that the e-learning tools within Strathmore were up-to-date, a laudable commendation to the University's IT Department. Still, majority (65\%) of the respondents assented that e-learning did add value to Strathmore University. An opposite opinion expressed by $57 \%$ of the respondents was that e-learning did not reduce expenditure on the part of students, contrary to what strategies like GOK (2006) anticipate. This meant that although the University was embarking on full scale adoption of ICT, there was need to put into consideration the low socioeconomic status of some of its students who were not able to access ICT facilities both within and outside the University. This meant that the lecturers needed to provide a back-up option for these students for instance giving the core materials during lectures. A financial scheme which gives credit to poor students could be designed.

\subsection{Output Strategies and Student Performance}

Two questions which dealt with whether tests were being given and the regularity of the tests were asked to answer the above research question. The researcher concentrated mainly on summative than formative evaluation. The responses yielded were that $21(42.9 \%)$ were not given tests using any form of e-learning and the tests were not regular $(18,36.7 \%$ were not given tests; 19 $(38.8 \%)$ only one test a semester and only $14 \%$ were given tests more than once a semester). In addition, if e-learning tools were to reap expected benefits, they had to be incorporated fully into the entire fabric of the organisation that it became invisible (Dublin, 2004). Some tests given using the traditional mode, like Introduction to Discrete Maths, Probability and Statistics and Business Mathematics, yielded better average scores than other units that incorporated elearning. This meant there was need to train the lecturers on how to incorporate e-learning effectively into the teaching and learning process.

\section{References}

Blass, E., \& Davis, A. (2003). Building on solid foundations: establishing criteria for e-learning development. Journal of Further and Higher Education, 27(3), 227-245.

Boon, J., Rusman, E., Van der Klink, M., \& Tattersall, C. (2005). Developing a critical view on e-learning trend reports: trend watching or trend setting? International Journal of Training and Development, 9(3), 205-211.

Dublin, L. (2004). The nine myths of e-learning implementation: ensuring the real return on your e-learning investment. Emerald 36(6), 291-294. 
Engelbrecht, E. (2003). A look at e-learning models: investigating their value for developing an e-learning strategy. Bureau for Learning Development, UNISA.

GOK. (2006). Kenya ICT Trust Fund: Strategic Plan. Nairobi: Author.

Jefferies, P., Carsten-Stahl, B., \& McRobb, S. (2007). Exploring the relationships between pedagogy, ethics and technology: building a framework for strategy development. Technology, Pedagogy and Education, $16(1), 111-126$.

Laurillard, D. (2006). E-Learning in Higher Education. In P. Ashwin (Ed.), Changing Higher Education: The Development of Learning and Teaching. London: Routledge.

Marshall, S. (2004). Applying SPICE to e-Learning: An e-Learning Maturity Model? Paper presented at the Sixth Australasian Computing Education Conference (ACE2004).

Pope, S. (2002). Form a successful strategy [Electronic Version]. E-learning, 34-37 from www.elearningmag.com.

Salmon, G. (2005). Flying not flapping: a strategic framework for e-learning and pedagogical innovation in higher education institutions. ALT-J, Research in Learning Technology, 13(3), 201-218.

Sharpe, R., Benfield, G., \& Francis, R. (2006). Implementing a university elearning strategy: levers for change within academic schools. ALT-J, Research in Learning Technology, 14(2), 135-151.

Web, E., Jones, A., Barker, P., \& Van Schaik, P. (2004). Using e-learning dialogues in higher education. Innovations in Education and Teaching International, 41(1), 93-103. 